\title{
Influence of Particle Size and Drug Load on Amorphous Solid Dispersions Containing pH-Dependent Soluble Polymers and the Weak Base Ketoconazole
}

\author{
Marius Monschke, ${ }^{1}$ Kevin Kayser, ${ }^{1}$ and Karl G. Wagner ${ }^{1,2}$
}

Received 31 August 2020; accepted 21 December 2020; published online 12 January 2021

\begin{abstract}
Among the great number of poorly soluble drugs in pharmaceutical development, most of them are weak bases. Typically, they readily dissolve in an acidic environment but are prone to precipitation at elevated $\mathrm{pH}$. This was aimed to be counteracted by the preparation of amorphous solid dispersions (ASDs) using the pHdependent soluble polymers methacrylic acid ethylacrylate copolymer (Eudragit L100-55) and hydroxypropylmethylcellulose acetate succinate (HPMCAS) via hot-melt extrusion. The hot-melt extruded ASDs were of amorphous nature and single phased with the presence of specific interactions between drug and polymer as revealed by X-ray powder diffraction (XRPD), differential scanning calorimetry (DSC), and Fourier-transform infrared spectroscopy (FT-IR). The ASDs were milled and classified into six particle size fractions. We investigated the influence of particle size, drug load, and polymer type on the dissolution performance. The best dissolution performance was achieved for the ASD made from Eudragit L100-55 at a drug load of $10 \%$, whereby the dissolution rate was inversely proportional to the particle size. Within a $\mathrm{pH}$-shift dissolution experiment (from $\mathrm{pH} 1$ to $\mathrm{pH}$ 6.8), amorphous-amorphous phase separation occurred as a result of exposure to acidic medium which caused markedly reduced dissolution rates at subsequent higher $\mathrm{pH}$ values. Phase separation could be prevented by using enteric capsules (Vcaps Enteric ${ }^{\circledR}$ ), which provided optimal dissolution profiles for the Eudragit L100-55 ASD at a drug load of 10\%.
\end{abstract}

KEY WORDS: Amorphous solid dispersions; Hot-melt extrusion; pH-dependent soluble polymers; Supersaturation.

\section{INTRODUCTION}

A fundamental problem in pharmaceutical development is the poor aqueous solubility of most of the new chemical entities. In many cases, the poor solubility entails a low oral bioavailability (1-4). Consequently, there is a need for formulation strategies which are capable to overcome this limitation. In the past, several approaches have been tested to address this by increasing the solubility or the dissolution rate of these compounds (5). Among these formulation approaches, amorphous solid dispersions (ASDs) were successfully applied. ASDs were shown to be able to enhance the oral bioavailability and there are several approved ASD

Guest Editors: Feng Zhang, Michael Repka and Suresh Bandari

${ }^{1}$ Department of Pharmaceutical Technology and Biopharmaceutics, University of Bonn, Gerhard-Domagk-Str. 3, 53121, Bonn, Germany.

${ }^{2}$ To whom correspondence should be addressed. (e-mail: karl.wagner@uni-bonn.de) formulations on the marked (6-8). An ASD consists of a drug, which is incorporated into a polymeric matrix, preferably in a molecularly dispersed state (single phase ASDs or solid solution) $(9,10)$. From a physical stability perspective, the polymer could prevent crystallization of the drug. Thereby the drug can be thermodynamically stabilized within the polymer, if the drug is dissolved in the matrix below its solubility limit (11). Alternatively, the drug can also be kinetically stabilized due to decreased molecular mobility $(12,13)$. ASDs usually cause supersaturated solutions upon dissolution as the drug is released out of its molecularly dispersed state facilitated by the high aqueous solubility and good wettability of the hydrophilic polymer (14). Once the drug is brought in solution, the supersaturated solution could also be stabilized by the precipitation inhibitory properties of the polymer through specific and unspecific interactions (1517). Ultimately, the generation of a supersaturation for a sufficient duration leads to an increased bioavailability (18). Several polymers have been tested as carriers for ASDs, the most commonly used polymers are those with immediate release characteristics, e.g., polyvinylpyrrolidone, 
copovidone, or hydroxypropyl cellulose (19). In addition, polymers with sustained release properties (20-22) or a $\mathrm{pH}-$ dependent solubility have also been applied successfully $(23,24)$. ASDs formulated using $\mathrm{pH}$-dependent soluble polymers as matrix featured several merits. These types of ASDs provided protection of the drug from the gastric juice, or were shown to be independent of the gastric $\mathrm{pH}$ value, since the dissolution is supposed to start in the intestinal region (25). Miller et al. (2008) showed that an ASD comprising of a $\mathrm{pH}-$ dependent soluble polymer caused a higher oral bioavailability as compared with an ASD based on an immediate release polymer (26).

The most common preparation techniques for ASDs are hot-melt extrusion (melt based) and spray-drying (solvent based) (7). For a hot-melt extrusion process, the material needs to be thermally stable and its melt viscosity should be in an acceptable range, additionally drug and polymer should be miscible in the ratio which is used $(27,28)$. If the requirements for the materials to be extruded are met, one could benefit from the variety of options with regard to the downstream processing. Different shapes of the extrusion strand can be generated by using different types of dies. In particular, the particle size of the ASD can be easily adjusted, by using sufficient milling techniques. Particle sizes are important for the control of the release properties (8). Zhang et al. (2018) compared very fine ASD particles obtained by spray-drying with coarse ASD particles obtained by hot-melt extrusion and they found that the production technique profoundly impacted the dissolution properties (29). Zheng et al. (2019) showed that the dissolution rate were inversely proportional to the particle size (30). However, also the recrystallization kinetics were dependent on the particle size since the extent of supersaturation and the supersaturation generation rate are determinative for the nucleation rate (31,32). These findings indicate a complex relation between ASD particle size and its actual performance. The complexity should even increase if a weakly basic drug is formulated as ASD due to its $\mathrm{pH}$-dependent solubility profile. Weakly basic drugs typically dissolve at low $\mathrm{pH}$ and potentially precipitate at elevated $\mathrm{pH}$ (above the $\mathrm{pK}_{\mathrm{A}}$ ) if the unionized form of the base is poorly soluble. As a consequence, those drugs often exhibit a low oral bioavailability as the intestinal $\mathrm{pH}$ is known to be neutral to basic (33-35). Several approaches aimed to overcome that issue by using acidifiers to modulate the microenvironmental $\mathrm{pH}$ (36-38). Zecevic et al. (2014) revealed that the enabling effect of an ASD comprising of a poorly soluble weak base together with an immediate release polymer was leveled as the drug precipitated upon transition to regions with elevated $\mathrm{pH}(24)$. Therefore, it would be desirable to create a formulation approach from which weakly basic drugs benefit at the intestinal $\mathrm{pH}$ region.

In this study, we formulated ASDs containing the poorly soluble weak base ketoconazole (KTZ) using two different $\mathrm{pH}$-dependent soluble polymers, namely, hydroxypropylmethylcellulose acetate succinate (HPMCAS LG) and methacrylic acid ethyl acrylate copolymer (Eudragit L100-55). By using pH-dependent soluble polymers, it was desired to convert the dissolution behavior (low dissolution at low $\mathrm{pH}$ and high dissolution at neutral $\mathrm{pH}$ ) of the weak base KTZ, with the highest possible dissolution performance at neutral $\mathrm{pH}$. However, at gastric $\mathrm{pH}$, the dissolution of a weak base within a pulverized formulation would be high, regardless of the type of the matrix functionality. We hypothesized that the particle size and drug load will be a decisive factor for the dissolution pattern of a weakly basic drug formulated as $\mathrm{pH}$-dependent soluble ASD. Therefore, a variety of particle sizes and two drug loads, respectively, were assessed to find a potential optimum regarding the dissolution performance. There is only limited information available about the influence of polymer type, drug load and particle size on the dissolution behavior of a $\mathrm{pH}$-dependent soluble ASD containing a weakly basic drug. The hot-melt extruded ASDs were analyzed regarding solid state using differential scanning calorimetry (DSC), X-ray powder diffraction (XRPD), and Fourier-transform infrared spectroscopy (FT-IR). Subsequently, the dissolution performance of the ASDs was tested at static $\mathrm{pH}$ (6.8). Additionally, a $\mathrm{pH}$-shift dissolution experiment (from acidic to neutral) was performed to study the influence of a biorelevant $\mathrm{pH}$ transition.

\section{MATERIAL AND METHODS}

\section{Materials}

The model drug ketoconazole was purchased from Fagron (Glinde, Germany). HPMCAS LG (glass transition temperature: $120^{\circ} \mathrm{C}$ ) was gifted from Shin-Etsu (Tokyo, Japan), and Eudragit L100-55 (glass transition temperature: $120^{\circ} \mathrm{C}$ ) was donated from Evonik (Darmstadt, Germany). PEG 3000 was obtained from Merck (Darmstadt, Germany). Vcaps Enteric ${ }^{\circledR}$ (consisting of HPMCAS) were donated by Capsugel (Morristown, NJ, USA).

\section{Hot-Melt Extrusion (HME)}

Prior extrusion, physical mixtures were blended for 10 min by aid of a turbula mixer (Willy A. Bachofen AG Maschinenfabrik, Switzerland). The ASDs were prepared using a ZE 12 Three-Tec $12 \mathrm{~mm}$ co-rotating twin screw extruder (Seon, Switzerland) with five heating zones and a functional length of 25:1 L/D equipped with a 2-mm die. The extruded compositions and the temperature profiles are listed in Table I. The feed rate and screw speed were kept constant at $2 \mathrm{~g} / \mathrm{min}$ and $100 \mathrm{rpm}$, respectively. For the formulations containing Eudragit L100-55, 10\% PEG 3000 as plasticizer was added to obtain an extrudable blend. This was necessary since Eudragit L100-55 exhibits a very high melt viscosity and preliminary experiments showed that the polymer alone could not be extruded as it caused a motor overload of the extruder.

Table I. Compositions of the formulations and extrusion temperature profiles

\begin{tabular}{lll}
\hline Composition & Ratio & Temp. $\left[{ }^{\circ} \mathrm{C}\right]$ \\
\hline HPMCAS LG:KTZ & $90: 10$ & $100 / 140 / 140 / 140 / 140$ \\
& $75: 25$ & $100 / 140 / 140 / 140 / 140$ \\
L100-55:PEG:KTZ & $80: 10: 10$ & $100 / 140 / 140 / 140 / 140$ \\
& $65: 10: 25$ & $100 / 140 / 140 / 140 / 140$ \\
\hline
\end{tabular}




\section{Preparation of Different Particle Sizes}

In order to investigate the influence of different particle sizes, six different particle fractions were prepared (Table II). For the manufacture of the finer particle fractions (125$45 \mu \mathrm{m}, 250-125 \mu \mathrm{m}$ and 500-250 $\mu \mathrm{m}$ ) a mixer mill 400 (Retsch, Haan, Germany) was used at $30 \mathrm{~Hz}$ for $30 \mathrm{~s}$ and for the manufacture of the coarser fractions a laboratory hammer mill with an inserted $2 \mathrm{~mm}$ sieve was used. Subsequently, the milled materials were classified using a sieve shaker (AS 200, Retsch, Haan, Germany) at an amplitude of $50 \%$ for 2 min with six different sieves with mesh sizes according to Table II.

\section{X-Ray Powder Diffraction (XRPD)}

For X-ray powder diffraction measurements an X'Pert MRD Pro (PANalytical, Almelo, the Netherlands) was used in reflection mode at $45 \mathrm{mV}$ and $40 \mathrm{~mA}$ with an $\mathrm{X}^{\prime}$ Celerator detector and nickel filtered $\mathrm{CuK} \alpha 1$ radiation. The scanning step size was $0.017^{\circ} 2 \theta$ in a range of $5^{\circ}$ to $45^{\circ} 2 \theta$.

\section{Differential Scanning Calorimetry (DSC)}

DSC experiments were carried out on a Mettler-Toledo DSC 2 equipped with a nitrogen cooling system (MettlerToledo, Gießen, Germany). The glass transition temperatures of the ASDs were determined using a multi-frequency temperature modulation (TOPEM-mode) with an underlying heating rate of $2 \mathrm{~K} / \mathrm{min}$ with a constant nitrogen purge $(30 \mathrm{ml} /$ min). Therefore, approximately $10 \mathrm{mg}$ of the respective sample was accurately weighed into aluminum pans and sealed with a pierced lid.

\section{Fourier-Transform Infrared Spectroscopy (FT-IR)}

Solid-state molecular interactions were assessed using a Bruker Alpha FT-IR spectrometer (Billerica, MA, USA) equipped with an attenuated total reflection (ATR) accessory. The spectral range was $400-4000 \mathrm{~cm}^{-1}$, and 24 scans were recorded for each sample. All raw materials, physical mixtures, and ASDs were measured.

\section{Phase Behavior Upon Immersion in Hydrochloric Acid}

In order to investigate a possible phase separation of the L100-55-based formulations, the ASD powder was immersed in $0.1 \mathrm{M}$ hydrochloric acid according to the acidic stage of the $\mathrm{pH}$-shift dissolution experiment. Subsequently, the powder was dried under vacuum at $40{ }^{\circ} \mathrm{C}$

Table II. Sieve fractions that were used to classify the milled ASDs

Sieve fraction $[\mu \mathrm{m}]$

1500-1000

$1000-710$

$710-500$

$500-250$

250-125

125-45 over night. Then, the dry ASD powder was assessed regarding solid state using DSC and FT-IR.

\section{Non-Sink Dissolution}

Supersaturating non-sink dissolution studies were conducted using the MiniDissolution apparatus, a miniaturized USP II apparatus with a volume of $20 \mathrm{ml}$ (28). The paddle speed was constant for all experiments at $100 \mathrm{rpm}$ and the temperature was set to $37{ }^{\circ} \mathrm{C}$. One dissolution experiment was conducted at a static $\mathrm{pH}$ of 6.8 using phosphate buffer for 3 h. Additionally, a $\mathrm{pH}$-shift dissolution experiment was carried out starting at $\mathrm{pH} 1$ using $0.1 \mathrm{M}$ hydrochloric acid for $1 \mathrm{~h}$, followed by an adjustment to $\mathrm{pH} 6.8$ with $1.9 \mathrm{ml}$ of a buffer concentrate consisting of $0.375 \mathrm{M}$ phosphate buffer and $0.85 \mathrm{M}$ sodium hydroxide. ASDs of each particle size fraction equivalent to $8 \mathrm{mg}$ ketoconazole were used for the dissolution experiments (theoretical concentration of $400 \mu \mathrm{g} / \mathrm{ml}$ ). The L100-55 ASD at a drug load of $10 \%$ was also filled into enteric capsules (Vcaps Enteric $®$ ) prior the pH-shift experiment.

The ketoconazole concentration was measured online using a diode array UV/VIS spectrophotometer (Agilent 8453, Agilent Technologies GmbH, Waldbronn, Germany) with correction for light scattering.

\section{RESULTS AND DISCUSSION}

\section{Solid State of the ASDs}

The solid state was investigated using XRPD and DSC. For pure KTZ sharp reflection peaks within the diffractogram were observed due to its crystalline structure (Fig. 1a). The crystalline nature of KTZ was confirmed by DSC measurements which revealed a melting point at $147{ }^{\circ} \mathrm{C}$. The ASDs comprising KTZ and either L100-55 or HPMCAS LG exhibited an amorphous halo within the diffractograms, indicating a complete transition of KTZ into the amorphous state. For all ASDs, single glass transition temperatures were observed. The glass transition temperatures of the L100-55based ASDs at 10 and $25 \%$ drug load were found at $80.6 \pm$ $1.2{ }^{\circ} \mathrm{C}$ and $73.0 \pm 0.7{ }^{\circ} \mathrm{C}$, respectively. The glass transition temperatures for the HPMCAS LG ASD at 10 and $25 \%$ drug load were found at $99.1 \pm 0.6^{\circ} \mathrm{C}$ and $83.8 \pm 0.6^{\circ} \mathrm{C}$, respectively (Fig. 1b). The presence of single glass transition temperatures clearly indicated the formation of single-phased ASDs.

The FT-IR spectrum of pure KTZ showed characteristic bands at $2963 \mathrm{~cm}^{-1}$ and $2883-2831 \mathrm{~cm}^{-1}$ originated by $\mathrm{CH}-$ vibrations, a $\mathrm{C}=\mathrm{O}$ stretching at $1644 \mathrm{~cm}^{-1}$ and an aromatic $\mathrm{C}=\mathrm{C}$ stretching at $1509 \mathrm{~cm}^{-1}$. L100-55 exhibited a $\mathrm{C}=\mathrm{O}$ double band at $1726 \mathrm{~cm}^{-1}$ (esterificated carboxylic groups) and $1698 \mathrm{~cm}^{-1}$ (carboxylic groups), whereby the latter band had a higher intensity. Pure HPMCAS LG showed a $\mathrm{C}=\mathrm{O}$ stretching vibration at $1732 \mathrm{~cm}^{-1}$ (Fig. 2).

For the physical mixtures of L100-55 and KTZ, the characteristic $\mathrm{C}=\mathrm{O}$ band from $\mathrm{KTZ}$ was still visible. This band completely vanished for the respective ASDs. Additionally, the shape of the $\mathrm{C}=\mathrm{O}$ double peak from the L100-55 changed, whereby the peak at $1726 \mathrm{~cm}^{-1}$ intensified compared with the one at $1698 \mathrm{~cm}^{-1}$. These peak transitions clearly indicate specific interactions between KTZ and the 
a

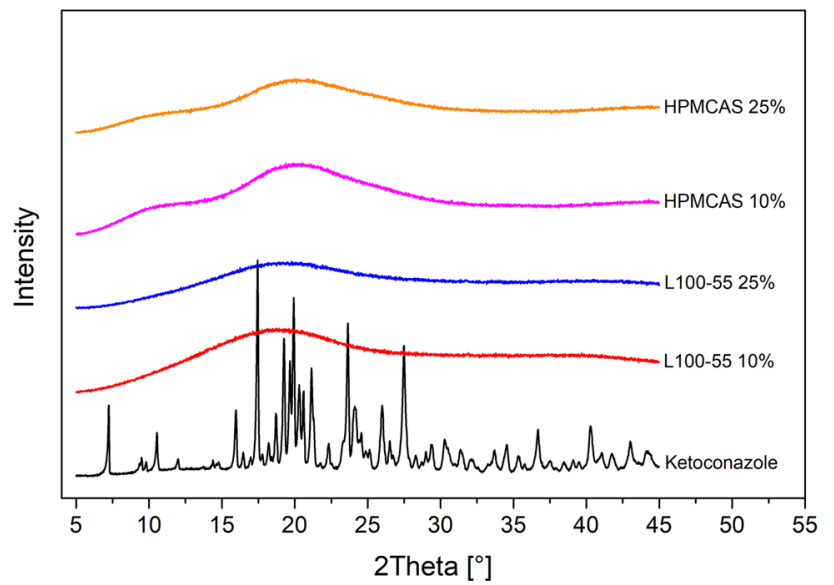

b

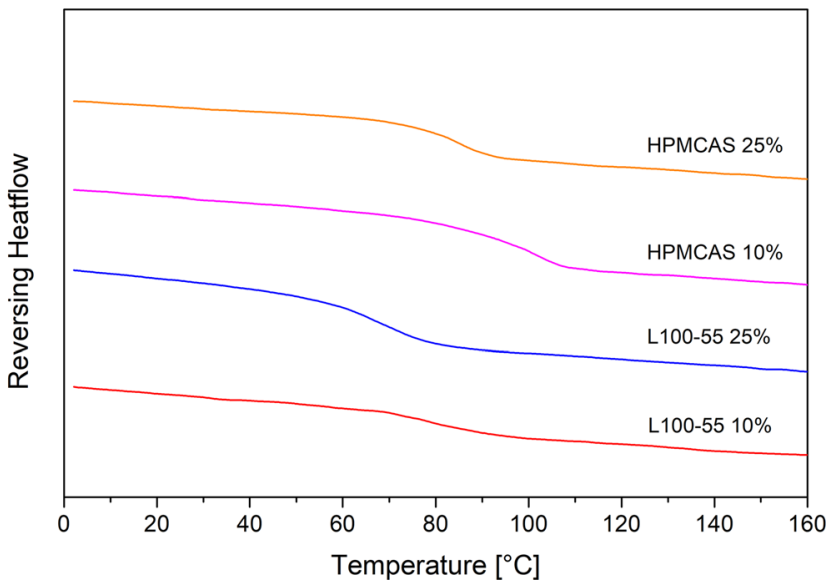

Fig. 1. Solid state of the ASDs. X-ray powder diffraction (XRPD) diffractograms (a). Differential scanning calorimetry (DSC) thermograms (b)

polymer. For the HPMCAS-based ASDs, similar observations could be made with regard to the peak of KTZ, which also vanished. However, no shift or shape change could be detected for the $\mathrm{C}=\mathrm{O}$ band at $1732 \mathrm{~cm}^{-1}$, which also indicated formation of specific interactions, but without participation of the carbonyl moiety of HPMCAS LG (Fig. 2).

\section{pH-Dependent Dissolution Behavior of Ketoconazole}

Ketoconazole is a weak base and consequently its dissolution behavior is expected to be highly $\mathrm{pH}$-dependent. In order to investigate the $\mathrm{pH}$-dependent dissolution behavior, a $\mathrm{pH}$-shift experiment was conducted. The initial $\mathrm{pH}$ was 1 , which was maintained for 1 hour to simulate the gastric stage; subsequently the $\mathrm{pH}$ was adjusted to $\mathrm{pH} 6.8$ for 4 hours to mimic the intestinal stage. As apparent from Fig. 3, KTZ dissolved to full extent within the acidic stage due to the fact that KTZ was present in its ionized form as a result of its basic nature. Upon the $\mathrm{pH}$ adjustment to 6.8 , a pronounced precipitation occurred to a concentration level of approximately $100 \mu \mathrm{g} / \mathrm{ml}$. However, this concentration level represented a supersaturated state of KTZ relative to the saturation solubility, which was caused by the $\mathrm{pH}$-shift. This

a

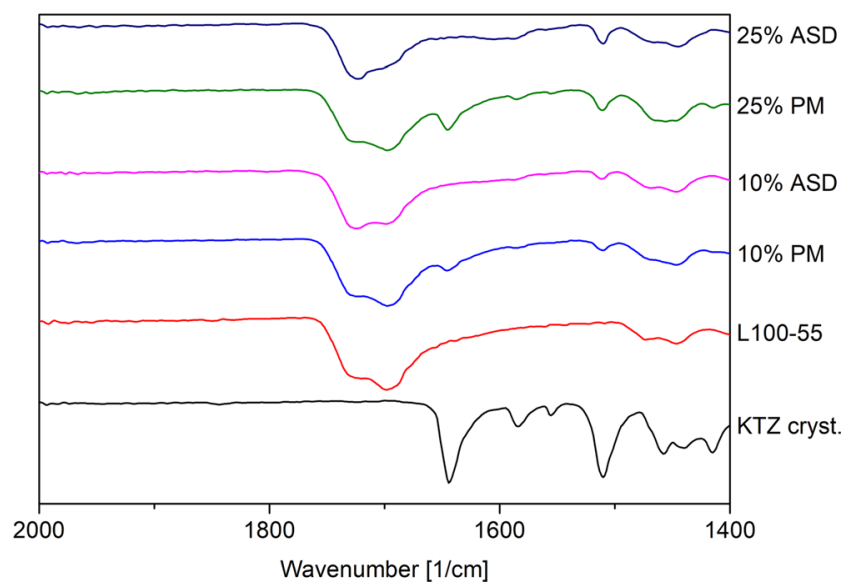

state was maintained for approximately $40 \mathrm{~min}$, which was followed by a further concentration drop to the level of the saturation solubility. Such a $\mathrm{pH}$-dependent solubility profile can be considered as problematic when it comes to absorption of such a molecule because of the low solubility at the site of absorption. Consequently, it would be desirable to create a formulation that achieves higher concentration at $\mathrm{pH} 6.8$.

\section{Dissolution Studies of the ASDs}

In order to assess the dissolution performance of the ASDs, two types of dissolution experiments were performed. Initially, the ASDs were tested using a static $\mathrm{pH}$ of 6.8. This experimental setup was selected in order to investigate the performance of the ASDs at conditions that are present at the site of absorption with regard to the $\mathrm{pH}$. The performance at these conditions can be considered as "best case scenario" since there is no further influencing factor that could alter/lower the performance of the ASDs. Consequently, the dissolution experiment at a static $\mathrm{pH}$ should provide insight of the theoretical performance of the ASDs at simulated site of absorption.

Subsequently, a pH-shift experiment was performed, which was supposed to be more representative for the physiological $\mathrm{pH}$ transition (from $\mathrm{pH} 1$ to $\mathrm{pH}$ 6.8). The

\section{b}

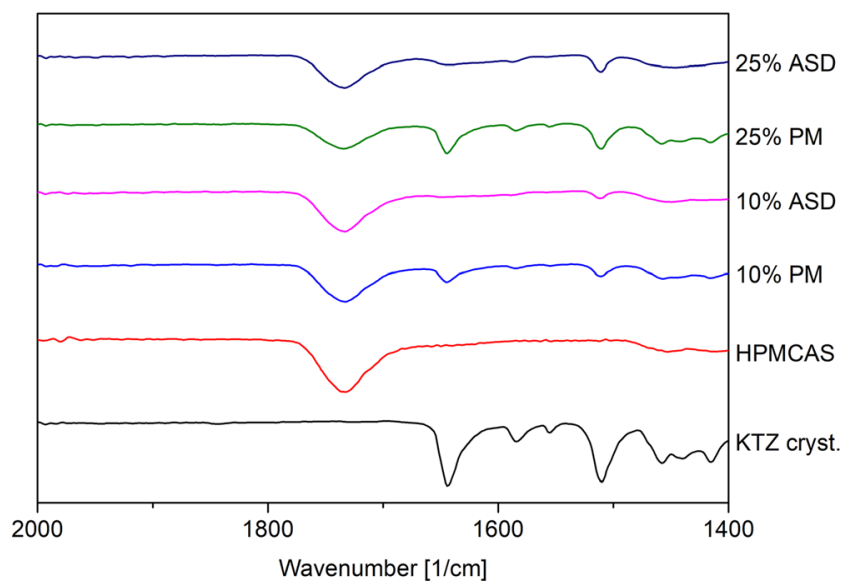

Fig. 2. Fourier-transform infrared spectra of KTZ-L100-55 formulations (a) and KTZ-HPMCAS LG formulations (b). PM physical mixture 


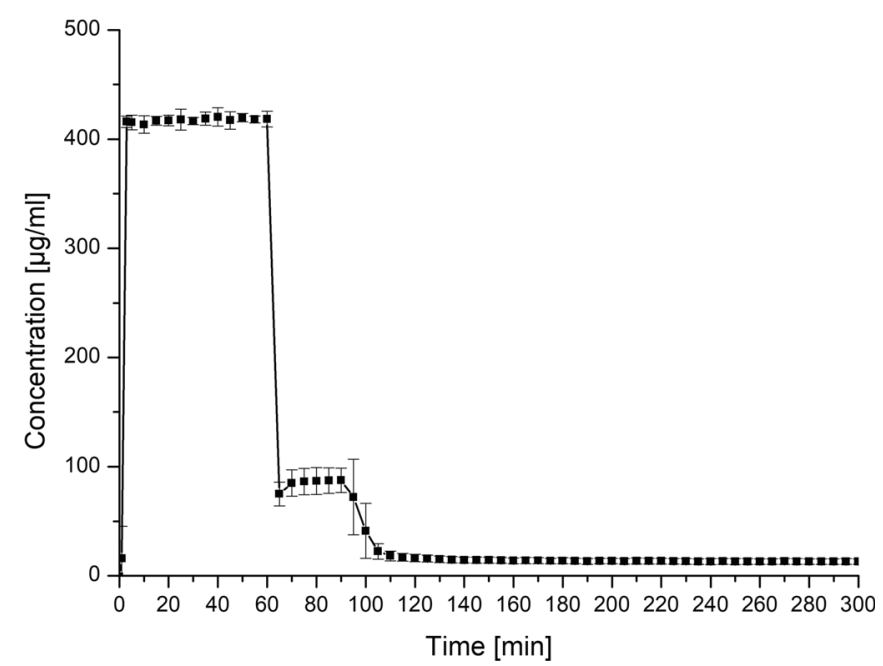

Fig. 3. $\mathrm{pH}$-shift dissolution experiment of neat $\mathrm{KTZ}(0-60 \mathrm{~min}$ : $\mathrm{pH} 1$; 60-300 min: $\mathrm{pH}$ 6.8)

general aim was to minimize the release extent at acidic $\mathrm{pH}$ and maximize the release at $\mathrm{pH}$ of 6.8 (i.e., inverting of the dissolution behavior of pure KTZ). Therefore, $\mathrm{pH}$-dependent soluble polymers were selected as ASD matrix, whose dissolution behavior is converse relative to pure KTZ. The potential to invert the dissolution behavior of KTZ was investigated as a function of polymer type, drug load, and particle size.

\section{Monophasic Non-Sink Dissolution at Static pH}

At first, the ASDs with six different particle fractions for each polymer and each drug load were tested in a dissolution test using a static $\mathrm{pH}$ of 6.8. Among the L100-55 ASD at a drug load of $10 \%$, the dissolution rate was dependent on the particle size. With decreasing particle size, the dissolution rate increased due to a higher specific surface area according to the Noyes-Whitney equation (39). For every particle size fraction, the maximum concentration of $400 \mu \mathrm{g} / \mathrm{ml}$ was approached and maintained in solution without occurrence of precipitation. Consequently, the polymer L100-55 had excellent precipitation inhibitory properties upon dissolution of a $10 \%$ drug load ASD and provided a desirable dissolution profile for KTZ (Fig. 4a). Among the different particle sizes of the L100-55 ASD at 25\% drug load, the rank order regarding the dissolution rate was dependent on the particle size analogous to the $10 \%$ drug load formulation. However, the maximum achieved concentration was only approximately $200 \mu \mathrm{g} / \mathrm{ml}$ for the finest fraction and $150 \mu \mathrm{g} / \mathrm{ml}$ for all other particle fractions. Additionally, precipitation occurred for all particle fractions, whereby a faster dissolution rate led to an earlier precipitation induction. This observation is in accordance with the study of Sun and Lee (2013) (32), as they found that the rate of supersaturation generation was proportional to the precipitation rate. The dissolution performance of the $25 \%$ drug load formulation was inferior compared with the $10 \%$ drug load as a consequence of a lower polymer concentration in solution upon dissolution of the ASD, which caused the inability to reach equally high concentrations and to maintain the supersaturated state (Fig. 4b). Several studies have shown that the polymer concentration is a critical factor for the level of supersaturation (i.e., amorphous solubility) and the course of the supersaturation over time. In most cases, both could be improved with an increased polymer concentration (i.e., lower drug load) (40-42).

For the HPMCAS-based ASDs, the initial dissolution behavior was also dependent on the particle size, whereby the dissolution rate increased with decreasing particle size as well. Among the $10 \%$ drug-loaded ASD particle fractions, the finest fraction resulted in the highest concentration level $(\sim 300 \mu \mathrm{g} / \mathrm{ml})$. All other fractions yielded lower concentrations. After approximately $60 \mathrm{~min}$ of a plateau phase, the concentration dropped to $50 \mu \mathrm{g} / \mathrm{ml}$ for all fractions (Fig. 4c). The HPMCAS-based ASDs with $25 \%$ drug load behaved very similar compared with the $10 \%$ drug load. Again, the dissolution rate was the fastest for the smallest fraction, and there was also a plateau phase with a subsequent drop in concentration to a level of $50 \mu \mathrm{g} / \mathrm{ml}$ after approximately $60 \mathrm{~min}$ (Fig. 4d). The similarity of the dissolution profiles revealed that the drug load (and total polymer concentration) had a minor impact on the dissolution rate and the supersaturation maintenance in the case of HPMCAS LG ASDs.

\section{pH-Shift Non-sink Dissolution}

Following the dissolution experiments at the static $\mathrm{pH}$ (6.8), a pH-shift dissolution experiment was conducted. This experiment was based on two $\mathrm{pH}$ stages, initially at $\mathrm{pH} 1$ for $60 \mathrm{~min}$; subsequently the $\mathrm{pH}$ was adjusted to 6.8 which was maintained for $240 \mathrm{~min}$. These conditions are supposed to mimic the $\mathrm{pH}$ transition in the human gastrointestinal tract. With this type of experimental setup, it was investigated to what extent the release of KTZ at acidic $\mathrm{pH}$ could be controlled via the particle size. Therefore, the least possible extent of release would be desirable, to avoid precipitation of KTZ upon pH-shift due to the absence of the polymer in solution as it is insoluble at acidic $\mathrm{pH}$. Consequently, the best scenario would be that the release of $\mathrm{KTZ}$ at acidic $\mathrm{pH}$ is close to zero while providing a rapid and complete release at $\mathrm{pH}$ 6.8. Additionally, it was intended to provide insight into 

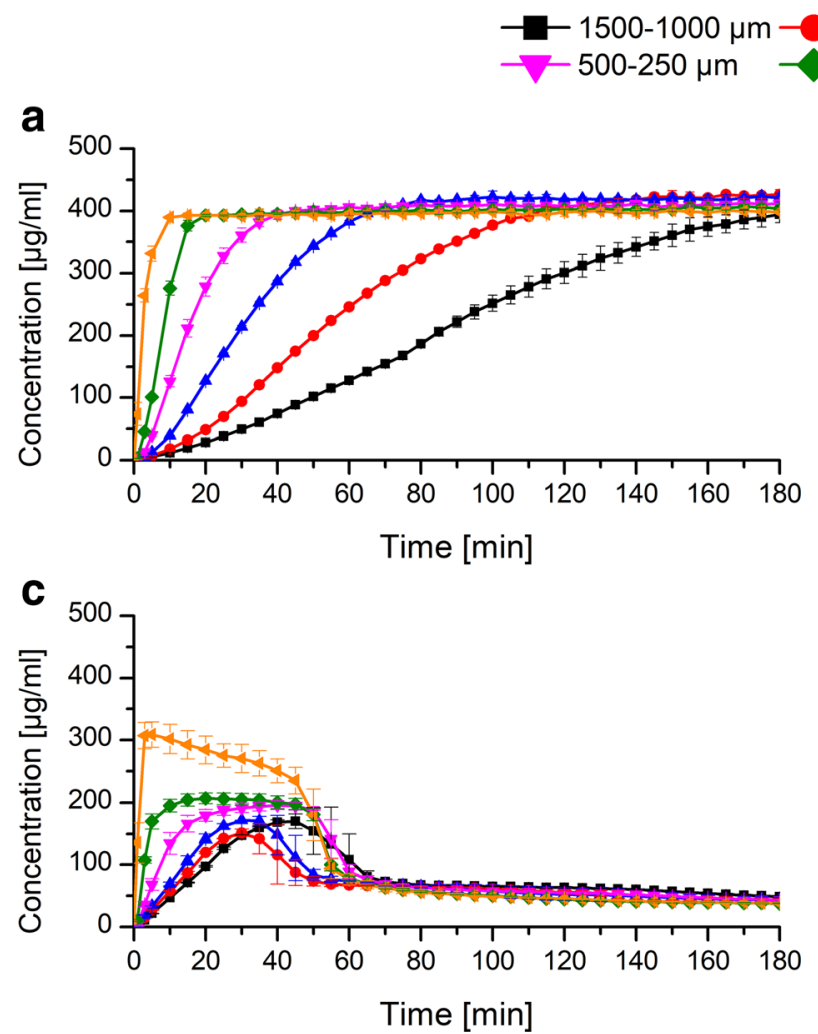

$$
\begin{aligned}
& 1000-710 \mu \mathrm{m}-710-500 \mu \mathrm{m} \\
& 250-125 \mu \mathrm{m}-125-45 \mu \mathrm{m}
\end{aligned}
$$

\section{b}
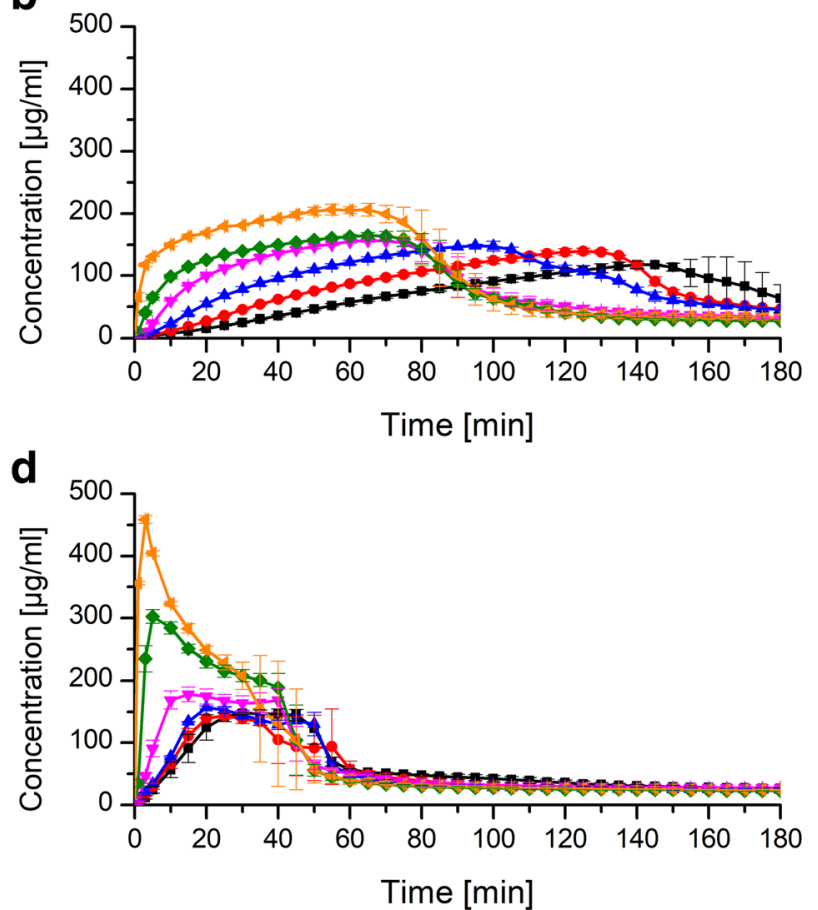

Fig. 4. Non-sink dissolution experiment at $\mathrm{pH} 6.8$ with different particle size fractions of ASDs of L100-55 (10\% drug load) (a), L100-55 (25\% drug load) (b), HPMCAS LG (10\% drug load) (c), and HPMCAS LG (25\% drug load) (d)

the influence of acidic exposure on the ASDs. In particular, the extent to which the acidic environment influenced the release at $\mathrm{pH} 6.8$ was questioned.

As for the L100-55 ASDs at 10\% drug load, almost no release of KTZ in the acidic stage was observed for the coarsest fraction $(1500-1000 \mu \mathrm{m})$, while for the finest fraction $(125-45 \mu \mathrm{m})$ a pronounced release was observed $(9 \mu \mathrm{g} / \mathrm{ml} v s$. $270 \mu \mathrm{g} / \mathrm{ml}$ ) (Fig. 5a). In general, the release of KTZ at pH 1 was inversely proportional to the particle size. As the specific surface area of the ASD particles increased with decreasing particle size, more KTZ molecules were thus exposed to the acidic medium for the finer fractions compared with the coarser fractions. It has to be considered that the polymer is insoluble in acidic medium; consequently the release of KTZ was only originated by KTZ being present on the surface and by diffusion through the hydrated polymer.

Upon adjustment of the $\mathrm{pH}$ to 6.8 , the polymer (L10055) started to dissolve. An increase in dissolution rate could consequently be observed for all fractions, except for the finest fraction. However, the dissolution rate and the reached concentration plateau were markedly reduced, compared with the performance at the static $\mathrm{pH}$ (6.8), as it only reached approximately half of the concentration level. The finest fraction of the L100-55 (10\% drug load) ASD deviated from the other particle fractions. After $60 \mathrm{~min}$, the resulting concentration was already at $270 \mu \mathrm{g} / \mathrm{ml}$ and subsequent to the $\mathrm{pH}$ adjustment, and a slight drop in concentration could be observed, likely due to precipitation of KTZ as a result of its $\mathrm{pH}$-dependent solubility (e.g., dissolution profile of neat KTZ). Additionally, immediately upon $\mathrm{pH}$-shift, there was no polymer in solution, which could have stabilized the KTZ in solution. However, after $120 \mathrm{~min}$, the concentration increased again to a final concentration of $297 \mu \mathrm{g} / \mathrm{ml}$, possibly as a result of the dissolution of the remaining intact ASD or redissolution of KTZ in presence of the dissolving polymer. Conclusively, the coarse fractions of the $10 \%$ drug loaded L100-55 ASD effectively retained the release of KTZ within the acidic stage, but none of the particle fractions could achieve concentration levels as tested in the static dissolution experiment after the $\mathrm{pH}$ adjustment.

For the L100-55-based ASD at a drug load of 25\%, the trend of the release of KTZ at the acidic stage was similar to the $10 \%$ drug load ASD (Fig. 5b). The extent was higher for each respective particle fraction since the higher drug load led to the fact that relatively more KTZ molecules were present on the ASD surface. However, for the three fine particle fractions (125-45 $\mu \mathrm{m} ; 250-125 \mu \mathrm{m} ; 500-250 \mu \mathrm{m})$, no concentration decrease occurred after the $\mathrm{pH}$ adjustment despite the fact that at this time point, only very a small amount of polymer (L100-55) was dissolved. Due to the high surface area of the finer particles, the polymer could dissolve very rapidly, which in turn could stabilize the supersaturated KTZ. As revealed in the static dissolution experiment, the polymer concentration was not sufficient to maintain the supersaturated level for the whole period; as a result precipitation occurred within the $\mathrm{pH}$-shift experiment, too. For the three coarser fractions, there was a limited release at $\mathrm{pH} 1$ and also upon pH-shift, the concentration level remained on a low level, and no increase in dissolution rate was observed (Fig. 5b).

While the coarse particle fractions of the HPMCASbased ASDs at $10 \%$ drug load effectively retained the release 


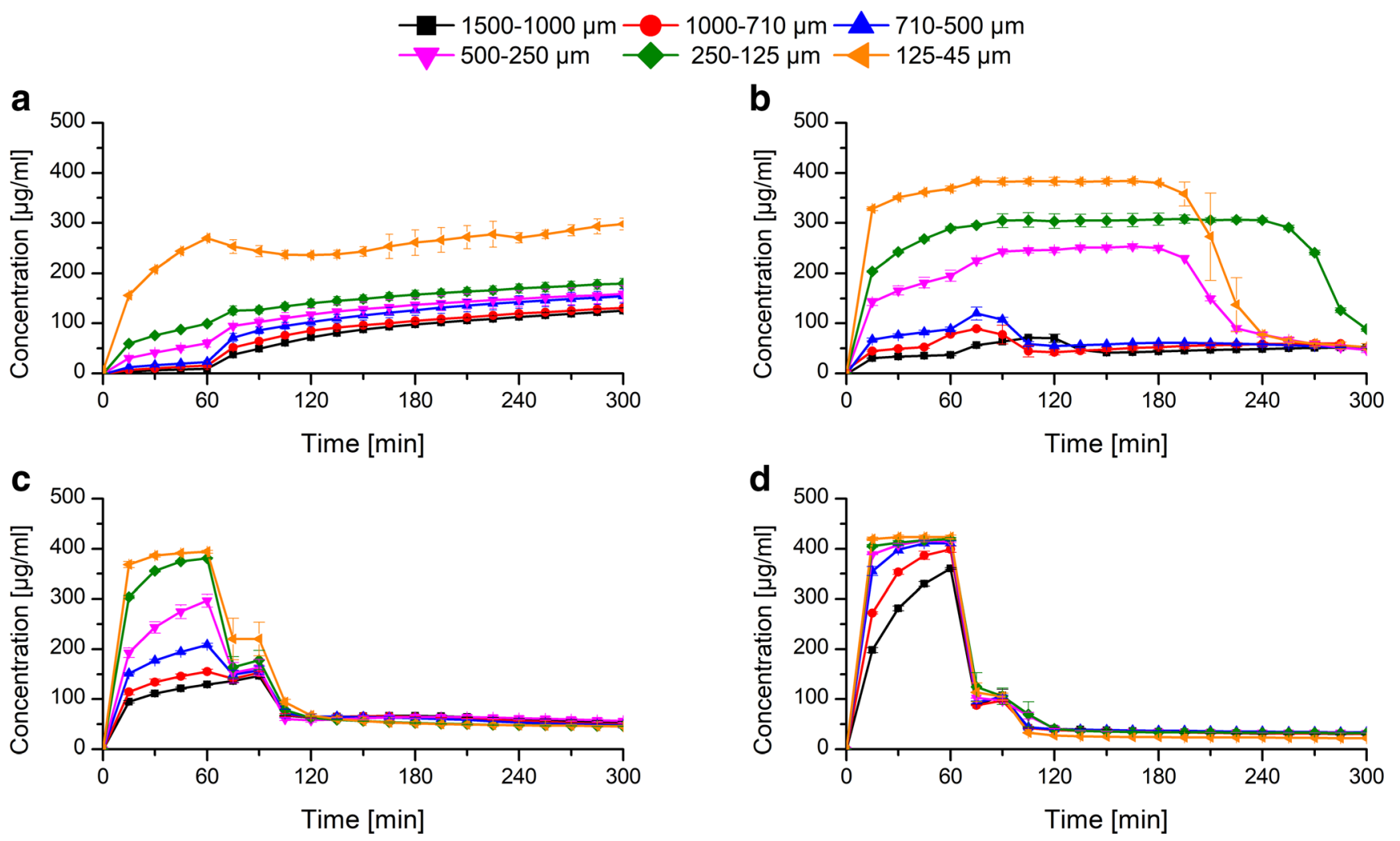

Fig. 5. pH-shift non-sink dissolution experiment (0-60 min: $\mathrm{pH} 1$; 60-300 min: $\mathrm{pH}$ 6.8) with different particle size fractions of ASDs of L100-55 at (10\% drug load) (a), L100-55 (25\% drug load) (b), HPMCAS LG (10\% drug load) (c), and HPMCAS LG (25\% drug load) (d)

of KTZ (Fig. 5c), at a drug load of $25 \%$, more KTZ was released at acidic $\mathrm{pH}$ due to relatively more KTZ molecules on the particle surface (Fig. 5d). With decreasing particle size, the dissolution profile for both drug loads approached the one of pure KTZ since the influence of the $\mathrm{pH}$-dependent soluble polymer decreased with increasing surface area. After the $\mathrm{pH}$-shift all HPMCAS-based ASD particle fractions showed a quantitative precipitation to the level of the solubility of KTZ as already observed by the static dissolution experiment. Consequently, the application of HPMCAS-based ASDs had no beneficial effect on the dissolution profile compared to pure KTZ because HPMCAS LG did not exhibit sufficient precipitation inhibiting effects. In order to potentially enhance the dissolution performance of HPMCAS-based ASDs, suitable surfactants might be added. It was shown that surfactants such as sodium lauryl sulfate or different types of poloxamer were able to improve the dissolution properties of HPMCAS-based ASDs $(43,44)$.

\section{Phase Separation upon Immersion in Hydrochloric Acid}

Due to the fact that the dissolution rate of the L100-55 ASDs was markedly reduced at $\mathrm{pH} 6.8$ when they were exposed to acidic medium, the phase behavior was investigated. Therefore, the ASD particles of both drug loads were immersed in $0.1 \mathrm{M}$ hydrochloric acid for $60 \mathrm{~min}$ according to the $\mathrm{pH}$-shift dissolution experiment. Subsequently, the particles were dried and analyzed using FT-IR and DSC. Figure 6 shows the FT-IR spectra of the ASDs, the respective physical mixtures, and the $\mathrm{HCl}$-treated ASDs. Within the FT-IR spectrum of the $\mathrm{HCl}-$ treated ASD (25\% drug load), the $\mathrm{C}=\mathrm{O}$ peak at $1644 \mathrm{~cm}^{-1}$ reappeared, which was not present within the spectrum of the ASD but in the spectrum of the physical mixture. Additionally, the peak shape of the $\mathrm{C}=\mathrm{O}$ double peak at $1698 \mathrm{~cm}^{-1}$ and $1732 \mathrm{~cm}^{-1}$ re-shaped towards the pattern of the physical mixture (indicated by the arrows in Fig. 6). The re-shaping of the $\mathrm{C}=\mathrm{O}$ double peak was also detected for the $10 \%$ drug-loaded ASD. These changes within the FT-IR spectra are indicative for an amorphous-amorphous phase separation (AAPS) within the ASD and a disruption of interactions between drug and polymer. Thereby, a drug-rich phase and a polymer-rich phase were formed (45).

The DSC measurement revealed changes in the glass transitions temperatures of the HCl-treated ASDs. Within the thermogram of the $25 \%$ drug loaded ASD, two distinct glass transition temperatures at $62.3^{\circ} \mathrm{C}$ and $101.4^{\circ} \mathrm{C}$ were found, which differed from the glass transition temperature of the untreated ASD $\left(73.0^{\circ} \mathrm{C}\right)$. For the $10 \%$ drug load ASD, a shift of the glass transition temperature from $80.6^{\circ} \mathrm{C}$ (untreated) to $68.3^{\circ} \mathrm{C}$ was found (Fig. 7). The shift of the glass transition temperatures towards lower temperatures and the occurrence of two distinct glass transition temperatures also indicated a formation of an AAPS and a disruption of interactions between drug and polymer. The lower glass transition temperature reflected the drug-rich phase and the higher one corresponded to the polymer-rich phase $(46,47)$.

The phenomenon of AAPS has been shown to be facilitated in presence of moisture as a consequence of an increased molecular mobility of the drug within the polymeric matrix $(48,49)$. The formation of a drug-rich phase and a polymer-rich phase has been shown to negatively influence 


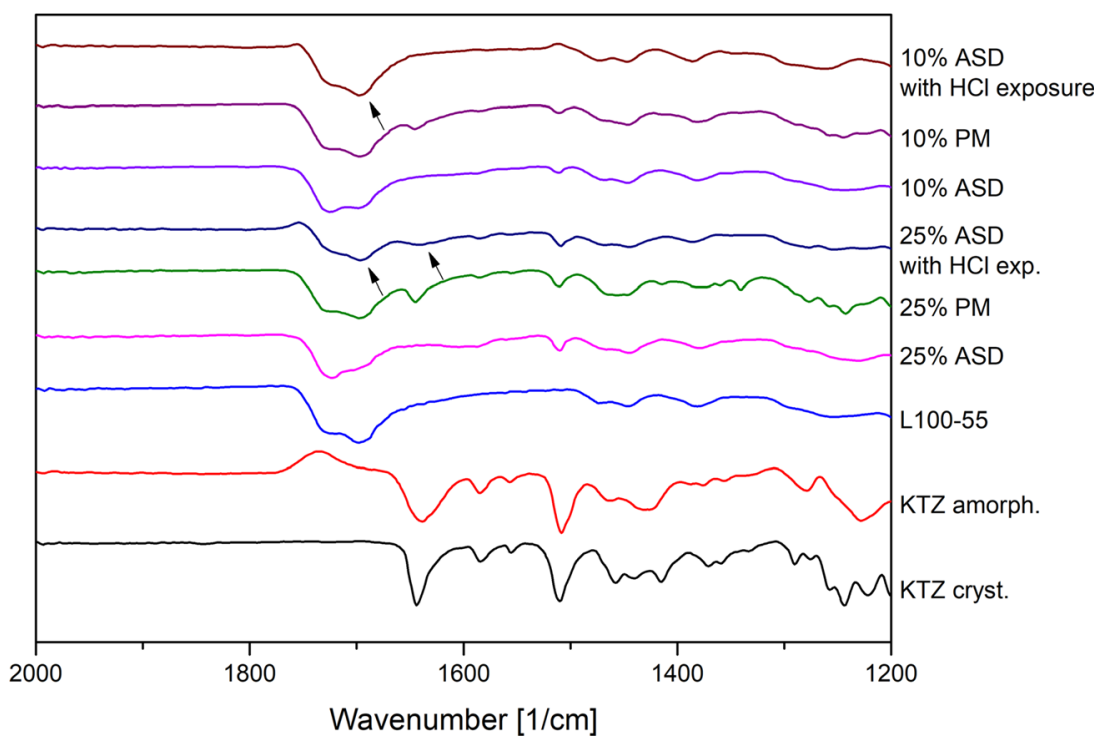

Fig. 6. Fourier-transform infrared spectra of crystalline KTZ, amorphous KTZ, neat L10055, physical mixtures and L100-55 ASDs (after preparation and after treatment with $\mathrm{HCl}$ )

the dissolution behavior as upon AAPS, a congruent release of drug and polymer could turn into an undesirable incongruent release of drug and polymer (50,51). An incongruent release could lead to the fact that the dissolution is drugcontrolled which was shown to profoundly decrease the dissolution rate of an ASD (48,52). These findings are in line with the observations within our study and explain the decreased dissolution rate after exposure to acidic medium. Despite the fact, that the release of KTZ at acidic $\mathrm{pH}$ could be effectively controlled by the particle size, the dissolution rate after $\mathrm{pH}$ shift was markedly reduced as a result of the occurrence of AAPS.

\section{pH-Shift Non-sink Dissolution Using Enteric Capsules}

By solely adjusting the particle sizes of the L100-55 ASDs, it was not possible to achieve an optimal dissolution behavior (i.e., close to zero release at acidic $\mathrm{pH}$ and rapid and complete release at neutral $\mathrm{pH}$ ), due to moisture-induced formation of a drug-rich and polymer-rich phase within the acidic stage. In order to avoid the exposure of the ASD particles to the acidic medium within the first dissolution stage, the $10 \%$ drug load L100-55 ASDs were filled into Vcaps Enteric ${ }^{\circledR}$. As these capsules consist of the polymer HPMCAS LG, they are supposed to be insoluble in acidic medium and would therefore be capable to protect the ASD particles from the acidic medium.

Figure 8 shows the dissolution results of the enteric capsules using the $\mathrm{pH}$-shift method. Within the acidic stage, no realease of KTZ took place. Following the $\mathrm{pH}$-shift to $\mathrm{pH} 6.8$, the capsule started to dissolve and the ASD particles were released. The dissolution behavior of the different ASD particle fractions resembled the dissolution profiles obtained in the static $\mathrm{pH}$ dissolution experiment, showing a complete

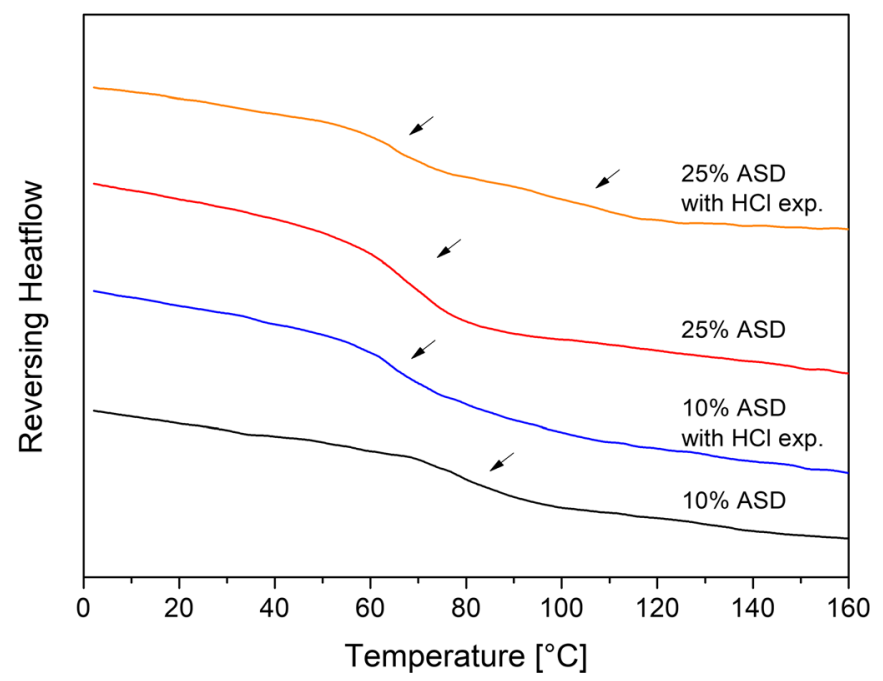

Fig. 7. Differential scanning calorimetry (DSC) thermograms of the L100-55 ASDs at 10 and 25\% drug load after preparation and after treatment with $\mathrm{HCl}$. Glass transition temperatures are indicated by the arrows 


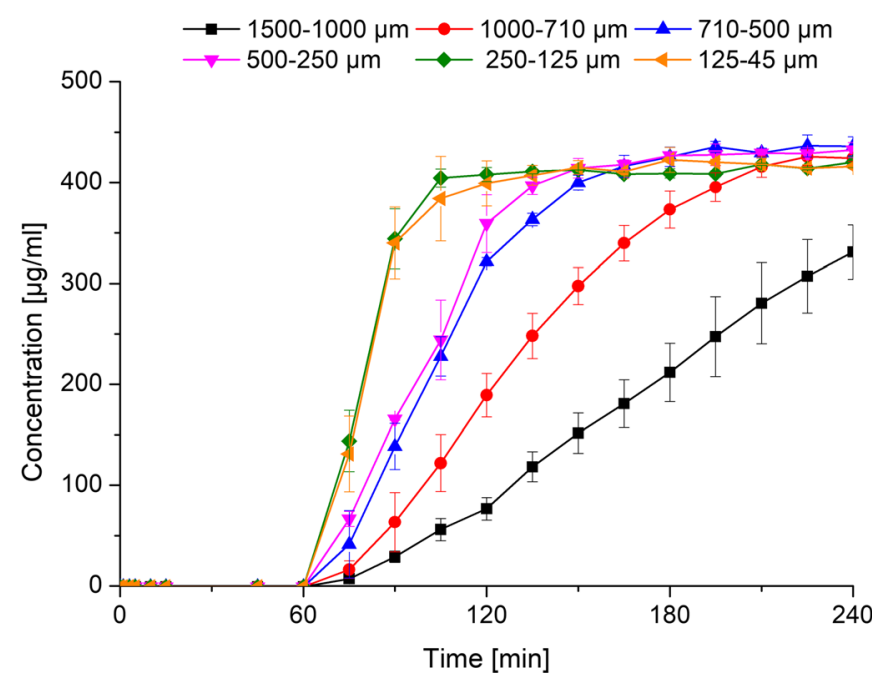

Fig. 8. $\mathrm{pH}$-shift non-sink dissolution experiment (0-60 min: $\mathrm{pH} 1$; 60-240 min: $\mathrm{pH}$ 6.8) with different particle size fractions of ASDs of L100-55 at (10\% drug load) filled into Vcaps Enteric ${ }^{\circledR}$

and rapid release depending on the particle sizes and additionally an absence of precipitation. This suggests that the enteric capsules effectively protected the ASD from the acidic medium and as a consequence the undesirable phase separation could be avoided, which led to dissolution properties as desired at elevated $\mathrm{pH}$. These findings highlight the potential of the application of enteric capsules for ASDs in general to ensure a sufficient dissolution performance by protecting the ASD formulations from adverse influencing factors such as acidic exposure.

\section{CONCLUSION}

In this study, we successfully prepared ASDs at two drug loads (10\% and 25\%) using Eudragit L100-55 and HPMCAS LG as pH-dependent soluble polymers and KTZ as weakly basic model drug by hot-melt extrusion. KTZ was transformed into its amorphous state and single-phase ASDs with specific interactions between drug and polymer were formed, as indicated by XRPD, DSC, and FT-IR measurements. The ASDs were then milled to obtain six different particle fractions. Subsequently, the influence of particle size, drug load and polymer type on the dissolution performance was studied. Initially, the dissolution performance was studied at a static $\mathrm{pH}$ of 6.8 , which revealed the most promising results for the L100-55 ASD at a drug load of $10 \%$ as a complete dissolution and a stable supersaturation without precipitation could be obtained. Thereby, the dissolution rate was inversely proportional the particle size. The dissolution of the L100-55 ASD at a drug load of $25 \%$ was markedly lower and the supersaturated level could not be maintained as a consequence of a lower polymer concentration in solution. Among the HPMCAS-based ASDs, a rapid initial release could be observed, but quantitative precipitation occurred in the course of the experiment, indicating a low precipitation inhibitory potential. In the following, a $\mathrm{pH}$-shift dissolution experiment (from $\mathrm{pH} 1$ to $\mathrm{pH}$ 6.8) was conducted to assess the influence of the acidic medium on the ASDs in general and specifically if the release of the weak base KTZ within the acidic stage could be controlled by the particle size. It was found that the most effective retaining of the release of KTZ in the acidic medium could be achieved by coarser particle fractions of the L100-55-based ASDs (close to zero for the coarsest particle fraction) as compared to the HPMCASbased ASDs. However, following the $\mathrm{pH}$-shift to $\mathrm{pH} 6.8$, the dissolution rate of the L100-55 ASD at 10\% drug load was markedly reduced compared to the static dissolution experiment for all particle fractions. This was due to the fact that an AAPS into a drug-rich phase and polymer-rich phase occurred during the exposure of ASDs to the acidic medium, which was identified by FT-IR and DSC. The occurrence of AAPS could successfully be prevented using enteric capsules (Vcaps Enteric $\AA$ ) since the ASDs were protected from the acidic medium. As a result, an optimal dissolution performance could be achieved for the L100-55-based ASD at a drug load of $10 \%$.

\section{ACKNOWLEDGMENTS}

We kindly thank Capsugel, Evonik and Shin-Etsu for providing samples.

\section{FUNDING}

Open Access funding enabled and organized by Projekt DEAL.

Open Access This article is licensed under a Creative Commons Attribution 4.0 International License, which permits use, sharing, adaptation, distribution and reproduction in any medium or format, as long as you give appropriate credit to the original author(s) and the source, provide a link to the Creative Commons licence, and indicate if changes were made. The images or other third party material in this article are included in the article's Creative Commons licence, unless indicated otherwise in a credit line to the material. If material is not included in the article's Creative Commons licence and your intended use is not permitted by statutory regulation or exceeds the permitted use, you will need to obtain permission directly from the copyright holder. To view a copy of this licence, visit http:// creativecommons.org/licenses/by/4.0/. 


\section{REFERENCES}

1. Pham-The H, Garrigues T, Bermejo M, González-Álvarez I, Monteagudo MC, Cabrera-Pérez MÁ. Provisional classification and in Silico study of biopharmaceutical system based on Caco2 cell permeability and dose number. Mol Pharm. 2013;10:244561.

2. Repka MA, Majumdar S, Kumar Battu S, Srirangam R, Upadhye SB. Applications of hot-melt extrusion for drug delivery. Expert Opinion on Drug Delivery. 2008;5:1357-76.

3. Teja SB, Patil SP, Shete G, Patel S, Bansal AK. Drug-excipient behavior in polymeric amorphous solid dispersions 2013;25.

4. Vo CL-N, Park C, Lee B-J. Current trends and future perspectives of solid dispersions containing poorly watersoluble drugs. Eur J Pharm Biopharm. 2013;85:799-813.

5. Kumar A, Sahoo SK, Padhee K, Kochar PPS, Satapathy A, Pathak N. Review on solubility enhancement techniques for hydrophobic drugs 2011;02:8.

6. Baghel S, Cathcart H, O'Reilly NJ. Polymeric amorphous solid dispersions: a review of amorphization, crystallization, stabilization, solid-state characterization, and aqueous solubilization of biopharmaceutical classification system class II drugs. J Pharm Sci. 2016;105:2527-44.

7. Pandi P, Bulusu R, Kommineni N, Khan W, Singh M. Amorphous solid dispersions: an update for preparation, characterization, mechanism on bioavailability, stability, regulatory considerations and marketed products. Int $\mathrm{J}$ Pharm. 2020;586:119560.

8. Pas T, Verbert S, Appeltans B, Van den Mooter G. The influence of crushing amorphous solid dispersion dosage forms on the in-vitro dissolution kinetics. Int $\mathrm{J}$ Pharm. 2020;573:118884.

9. Chiou WL, Riegelman S. Pharmaceutical applications of solid dispersion systems. J Pharm Sci. 1971;60:1281-302.

10. Okonogi S, Oguchi T, Yonemochi E, Puttipipatkhachorn S, Yamamoto K. Improved dissolution of ofloxacin via solid dispersion. Int J Pharm. 1997;156:175-80.

11. Bochmann ES, Neumann D, Gryczke A, Wagner KG. Microscale prediction method for API-solubility in polymeric matrices and process model for forming amorphous solid dispersion by hot-melt extrusion. Eur J Pharm Biopharm. 2016;107:40-8.

12. Hancock BC, Shamblin SL, Zografi G. Molecular mobility of amorphous pharmaceutical solids below Their glass transition temperatures. Pharm Res. 1995;12:799-806.

13. Yuan X, Sperger D, Munson EJ. Investigating miscibility and molecular mobility of Nifedipine-PVP amorphous solid dispersions using solid-state NMR spectroscopy. Mol Pharm. 2014;11:329-37.

14. Vasconcelos T, Sarmento B, Costa P. Solid dispersions as strategy to improve oral bioavailability of poor water soluble drugs. Drug Discov Today. 2007;12:1068-75.

15. Ilevbare GA, Liu H, Edgar KJ, Taylor LS. Maintaining Supersaturation in aqueous drug solutions: impact of different polymers on induction times. Cryst Growth Des. 2013;13:74051.

16. Ilevbare GA, Liu H, Edgar KJ, Taylor LS. Understanding polymer properties important for crystal growth inhibition-impact of chemically diverse polymers on solution crystal growth of ritonavir. Cryst Growth Des. 2012;12:3133-43.

17. Monschke M, Wagner KG. Impact of HPMCAS on the dissolution performance of polyvinyl alcohol Celecoxib amorphous solid dispersions. Pharmaceutics. 2020;12:541.

18. Boyd BJ, Bergström CAS, Vinarov Z, Kuentz M, Brouwers J, Augustijns P, et al. Successful oral delivery of poorly watersoluble drugs both depends on the intraluminal behavior of drugs and of appropriate advanced drug delivery systems. Eur J Pharm Sci. 2019;137:104967.

19. Kallakunta VR, Sarabu S, Bandari S, Tiwari R, Patil H, Repka MA. An update on the contribution of hot-melt extrusion technology to novel drug delivery in the twenty-first century: part I. Expert Opinion on Drug Delivery. 2019;16:539-50.

20. Fan W, Zhang X, Zhu W, Di L. The preparation of Curcumin sustained-release solid dispersion by hot-melt extrusion-II.
Optimization of preparation process and evaluation in vitro and in vivo. J Pharm Sci. 2020;109:1253-60.

21. Lugtu-Pe JA, Ghaffari A, Chen K, Kane A, Wu XY. Development of controlled release amorphous solid dispersions (CRASD) using polyvinyl acetate-based release retarding materials: effect of dosage form design. Eur J Pharm Sci. 2018;124:319-27.

22. Tran PH-L, Tran TT-D, Park JB, Lee B-J. Controlled release systems containing solid dispersions: strategies and mechanisms. Pharm Res. 2011;28:2353-78.

23. Monschke M, Kayser K, Wagner KG. Processing of polyvinyl acetate phthalate in hot-melt extrusion-preparation of amorphous solid dispersions. Pharmaceutics. 2020;12:337.

24. Zecevic DE, Meier R, Daniels R, Wagner K-G. Site specific solubility improvement using solid dispersions of HPMC-AS/ HPC SSL - mixtures. Eur J Pharm Biopharm. 2014;87:264-70.

25. Monschke M, Wagner KG. Amorphous solid dispersions of weak bases with $\mathrm{pH}$-dependent soluble polymers to overcome limited bioavailability due to gastric $\mathrm{pH}$ variability - an in-vitro approach. Int J Pharm. 2019;564:162-70.

26. Miller DA, DiNunzio JC, Yang W, McGinity JW, Williams RO. Enhanced in vivo absorption of Itraconazole via stabilization of Supersaturation following acidic-to-neutral $\mathrm{pH}$ transition. Drug Dev Ind Pharm. 2008;34:890-902.

27. LaFountaine JS, McGinity JW, Williams RO. Challenges and strategies in thermal processing of amorphous solid dispersions: a Review. AAPS PharmSciTech. 2016;17:43-55.

28. Zecevic DE, Wagner KG. Rational development of solid dispersions via hot-melt extrusion using screening, material characterization, and numeric simulation tools. J Pharm Sci. 2013;102:2297-310.

29. Zhang D, Lee Y-C, Shabani Z, Frankenfeld Lamm C, Zhu W, Li $\mathrm{Y}$, et al. Processing impact on performance of solid dispersions. Pharmaceutics. 2018;10:142.

30. Zheng K, Lin Z, Capece M, Kunnath K, Chen L, Davé RN. Effect of particle size and polymer loading on dissolution behavior of amorphous Griseofulvin powder. J Pharm Sci. 2019;108:234-42.

31. Sun DD, Lee PI. Evolution of Supersaturation of amorphous pharmaceuticals: nonlinear rate of Supersaturation generation regulated by matrix diffusion. Mol Pharm. 2015;12:1203-15.

32. Sun DD, Lee PI. Evolution of Supersaturation of amorphous pharmaceuticals: The effect of rate of Supersaturation generation. Mol Pharm. 2013;10:4330-46.

33. Hamed R, Awadallah A, Sunoqrot S, Tarawneh O, Nazzal S, AlBaraghthi $\mathrm{T}$, et al. $\mathrm{pH}$-dependent solubility and dissolution behavior of Carvedilol-case example of a weakly basic BCS class II drug. AAPS PharmSciTech. 2016;17:418-26.

34. Kataoka M, Fukahori M, Ikemura A, Kubota A, Higashino H, Sakuma S, et al. Effects of gastric $\mathrm{pH}$ on oral drug absorption: in vitro assessment using a dissolution/permeation system reflecting the gastric dissolution process. Eur J Pharm Biopharm. 2016;101:103-11.

35. Rubbens J, Brouwers J, Tack J, Augustijns P. Gastrointestinal dissolution, supersaturation and precipitation of the weak base indinavir in healthy volunteers. Eur J Pharm Biopharm. 2016;109:122-9.

36. Choi J-S, Kwon S-H, Lee S-E, Jang WS, Byeon JC, Jeong HM, et al. Use of acidifier and solubilizer in tadalafil solid dispersion to enhance the in vitro dissolution and oral bioavailability in rats. Int J Pharm. 2017;526:77-87.

37. Espinoza R. Influence of admixed citric acid on the release profile of pelanserin hydrochloride from HPMC matrix tablets. Int J Pharm. 2000;201:165-73.

38. Mitra A, Kesisoglou F, Beauchamp M, Zhu W, Chiti F, Wu Y. Using absorption simulation and gastric $\mathrm{pH}$ modulated $\mathrm{dog}$ model for formulation development to overcome Achlorhydria effect. Mol Pharm. 2011;8:2216-23.

39. Noyes AA, Whitney WR. The rate of solution of solid substances in their own solutions. J Am Chem Soc. 1897;19:930-4.

40. Blaabjerg L, Grohganz H, Lindenberg E, Löbmann K, Müllertz A, Rades T. The influence of polymers on the Supersaturation potential of poor and good glass formers. Pharmaceutics. 2018;10:164 
41. Cheng H, Mao L, Zhang S, Lv H. Impacts of polymeric additives on nucleation and crystal growth of indomethacin from supersaturated solutions. AAPS PharmSciTech. 2019;20:193.

42. Ueda K, Higashi K, Yamamoto K, Moribe K. Inhibitory effect of Hydroxypropyl methylcellulose acetate succinate on drug recrystallization from a supersaturated solution assessed using nuclear magnetic resonance measurements. Mol Pharm. 2013;10:3801-11.

43. Solanki NG, Lam K, Tahsin M, Gumaste SG, Shah AV, Serajuddin ATM. Effects of surfactants on ItraconazoleHPMCAS solid dispersion prepared by hot-melt extrusion I: miscibility and drug release. J Pharm Sci. 2019;108:1453-65.

44. Kallakunta VR, Sarabu S, Bandari S, Batra A, Bi V, Durig T, et al. Stable amorphous solid dispersions of fenofibrate using hot melt extrusion technology: effect of formulation and process parameters for a low glass transition temperature drug. Journal of Drug Delivery Science and Technology. 2020;58:101395.

45. Rumondor ACF, Wikström H, Van Eerdenbrugh B, Taylor LS. Understanding the tendency of amorphous solid dispersions to undergo amorphous-amorphous phase separation in the presence of absorbed moisture. AAPS PharmSciTech. 2011;12:120919.

46. Chen Y, Pui Y, Chen H, Wang S, Serno P, Tonnis W, et al. Polymer-mediated drug Supersaturation controlled by drugpolymer interactions persisting in an aqueous environment. Mol Pharm. 2019;16:205-13.
47. Purohit HS, Taylor LS. Phase separation kinetics in amorphous solid dispersions upon exposure to water. Mol Pharm. 2015;12:1623-35.

48. Han YR, Ma Y, Lee PI. Impact of phase separation morphology on release mechanism of amorphous solid dispersions. Eur J Pharm Sci. 2019;136:104955.

49. Vasanthavada M. Tong W-Q (Tony), Joshi Y, Kislalioglu MS. phase behavior of amorphous molecular dispersions II: role of hydrogen bonding in solid solubility and phase separation kinetics. Pharm Res. 2005;22:440-8.

50. Purohit HS, Taylor LS. Phase behavior of ritonavir amorphous solid dispersions during hydration and dissolution. Pharm Res. 2017;34:2842-61.

51. Saboo S, Taylor LS. Water-induced phase separation of miconazole-poly (vinylpyrrolidone-co-vinyl acetate) amorphous solid dispersions: insights with confocal fluorescence microscopy. Int J Pharm. 2017;529:654-66.

52. Saboo S, Mugheirbi NA, Zemlyanov DY, Kestur US, Taylor LS. Congruent release of drug and polymer: a "sweet spot" in the dissolution of amorphous solid dispersions. J Control Release. 2019;298:68-82.

Publisher's Note Springer Nature remains neutral with regard to jurisdictional claims in published maps and institutional affiliations. 